\title{
The effect of output growth volatility on output growth: empirical evidence from Turkey
}

\author{
Volkan Ülke ${ }^{a}$, Serdar Varlik ${ }^{b}$ and M. Hakan Berument (i) ${ }^{c}$ \\ ${ }^{a}$ Faculty of Economics and Social Sciences, International Burch University, Sarajevo, Bosnia and Herzegovina; ${ }^{b}$ Department of Economics, \\ Hitit University, Corum, Turkey; 'Department of Economics, Bilkent University, Ankara, Turkey
}

ABSTRACT

This article assesses the effect of output growth volatility on output growth within a stochasticvolatility-in-mean model with a time-varying framework for an open small economy: Turkey. Until now, the empirical evidence on industrial production mainly reveals that this relationship is negative. However, in further examining different sectors and sub-sectors of industrial production, we find the sign of the relationship changes depending on the sector. Moreover, there is limited evidence that the sign of the relationship changes over time. Thus, the evidence reveals that the nature of the output growth volatility-output growth relationship is not uniform across sectors.

\section{KEYWORDS}

Output growth volatility; output growth; TVP-SVM

JEL CLASSIFICATION E23; E10; O40; C52

\section{Introduction}

The link between output and its volatility is one of the most examined issues in macroeconomics, and there are various arguments on the nature of this relationship. ${ }^{1}$ Friedman (1968) argues that output and volatility are independent from each other. Sandmo (1970) and Black (1987) argue that output volatility has a positive effect on output. Keynes (1936), Pindyck (1991), and Ramey and Ramey (1995), the last of which is considered a benchmark empirical study of the relationship between aggregate output and its volatility, argue that the effect of output volatility on output is negative. Hakura (2007) supports the negative effect and reports that emerging economies are more sensitive to aggregate output volatility than developed economies. Imbs (2007) investigates this relationship across countries as well as across sectors. He reports that even if the relationship is negative across countries, it is positive across sectors. The present study is an attempt to understand the relationship between output volatility and output by considering its sub-components on different sectors individually across time. To be specific, we investigate the relationship between industrial production and its volatility on the aggregate industrial production (IP) level and its sub-sectors for an important emerging economy Turkey - by using Chan's (2017) novel stochasticvolatility-in-mean model with time-varying parameters (TVP-SVM).

Friedman (1968), Phelps (1968), and Lucas (1972) use misperception theory, which suggests no relationship between output and its volatility. They argue that the main factors of output growth are real factors such as labour and technology, and that price misperceptions, which are the result of monetary shocks, cause fluctuations in output. Thus, there should be no relationship between output and its volatility. This argument is a reflection of the standard classic dichotomy in macroeconomics, which suggests that there is no relationship between output and its volatility. There are also empirical studies that support the above authors' proposition. For example, Speight (1999) finds no significant relationship between output variability and growth using models of generalized autoregressive conditional heteroscedasticity (GARCH) in the mean for the UK, which were applied to post-war monthly industrial production data. Fang and Miller (2008) report no statistically significant relationship between output

\footnotetext{
CONTACT M. Hakan Berument berument@bilkent.edu.tr D Department of Economics, Bilkent University, Ankara 06800, Turkey

${ }^{1}$ See Tsouma (2014) for a theoretical and empirical literature review.

(c) 2018 Informa UK Limited, trading as Taylor \& Francis Group
} 
growth rate and its volatility for the US between 1947 and 2006.

The positive effect of output volatility on output can be observed under the condition of precautionary saving or investment on high-return technologies. Sandmo (1970) argues that higher income volatility causes a higher saving rate for precautionary reasons, which results in a higher growth rate. Black (1987) claims that investment in riskier technologies is realized when there is a high return expectation, therefore leading to a higher growth rate. More recent empirical studies that present the positive impact of output volatility on output include Lee (2010) and Zagler (2016). Lee (2010) reports a positive effect of volatility on output growth for G7 countries between 1965 and 2007 using a dynamic panel GARCH specification. Zagler (2016) shows a positive relation between long-run output volatility and economic growth for 25 OECD countries using data between 1960 and 2013. Economic structure and other externalities may also affect the relationship between output volatility and output. For example, Dawson (2015) considers the role of economic freedom in the output and output volatility nexus for a diverse sample of 99 countries. He shows that output volatility more likely has a negative effect in low-freedom countries. Indeed, empirical studies report a positive effect of output volatility on output, especially for developed countries. Thus, this finding may suggest that the nature of volatility impact on output can be negative for emerging economies.

The adverse effect of output volatility on output is based on the proposition of Keynes (1936), who claims that when making a decision about investment, investors consider economic conditions. High output volatility is considered a risk for investment, which reduces the demand for it. Therefore, output growth should be lower. Pindyck (1991) elaborates on irreversible investment expenditures and political and economic instability, which negatively affect the decision to invest. Moreover, uncertainty has a negative effect on investment, and hence an adverse effect on growth rate. Ramey and Ramey (1995), in their pioneering empirical study, show that higher output volatility results in lower growth rates for 92 countries. Dabušinskas, Kulikov, and Randveer
(2013) reinforce Ramey and Ramey's (1995) result, showing a negative impact of output volatility in a panel of 121 countries between 1980 and 2010 . Hakura (2007) finds that in addition to its negative effect, the effect of output volatility is bigger in developing countries than in developed countries. Furthermore, Kose, Prasad, and Terrones (2006) show a basic negative association between output volatility and growth during the 1990s, and emphasize that both trade and financial integration significantly weaken this negative relationship.

In addition to these panel studies, the output volatility-growth relationship has been examined for single-country cases. For example, Berument, Dincer, and Mustafaoglu (2012) present the negative impact of growth volatility on growth for Turkey between 1987 and 2007. Tsouma (2014) investigates the negative impact for Greece from 1975 to mid-2013. Therefore, the negative impact of aggregate output volatility on aggregate output is an accepted suggestion, especially for emerging economies.

Overall, one may expect a negative effect of output volatility on output for developing or emerging economies, as well as low economic freedom. However, individual sectoral growth and its volatility association is a hitherto neglected topic. To the best of our knowledge, there has been no study exploring this relationship for different sectors. The only study that considers sectoral data is Imbs' (2007) work, and he considers the relationship across sectors rather than on individual sectors at a certain time. He reports a negative relationship across countries but a positive relationship across sectors. In an earlier version of the article (Imbs 2002, 16), he calls this phenomenon an example of 'Simpson's fallacy.' The current article, to the best of our knowledge, is the first that considers this relationship for a set of sectors.

On the econometric methodology for the effects of output volatility on output, the main methodology to assess this relationship is an ARCH-type model that provides the direct effect of a variable's conditional variance on its level (Evans 1991). Koopman and Uspensky (2002) propose the SVM model, which enables observing variability as a stochastic variable rather than as a 
deterministic variable, as occurs in ARCH-type models. Chan (2017) extends the SVM model with TVPs to explore the effect of volatility on output growth (the TVP-SVM model).

Our methodology incorporates possible structural breaks between output growth volatility and the output growth relationship that previous methodologies seem to have overlooked. This article examines the impact of output growth volatility on output growth for different aggregation levels in Turkey, an important emerging economy and the seventeenth largest in the world in 2015 (according to the World Bank's PPP-based ${ }^{2}$ GDP ranking). As Turkey also has a large variability in output (see Figure 1(b)), there is a low change in
type-II error (failing to reject the null when it is false) for the data.

The contributions of the article are as follows: First, this is the premier article to consider growth and its volatility association using a TVP model, which allows us to compare the effect of output growth volatility across time. Second, this article assesses growth and its volatility at different aggregation levels as well as for different sub-sectors for a single country.

The empirical evidence gathered from the NACE Rev.2 classification industrial production (IP) series suggests that the effect of output growth volatility on output growth is negative. When this parameter is estimated for the three

(a) Aggregate output growth

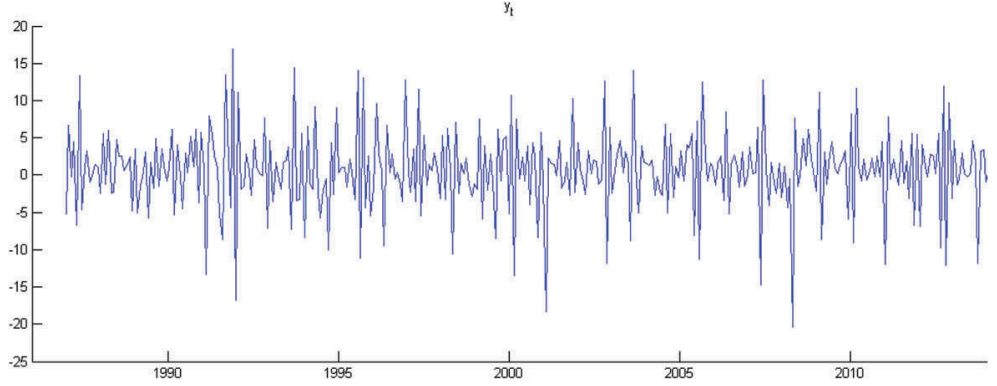

(b) Aggregate output growth volatility $\left(h_{t}\right)$

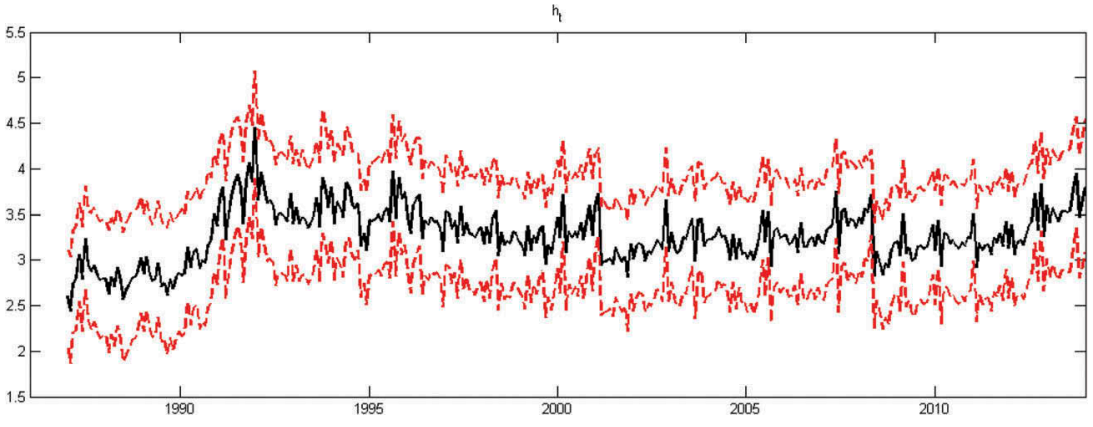

(c) Estimate of $\alpha_{t}$ for aggregate output growth

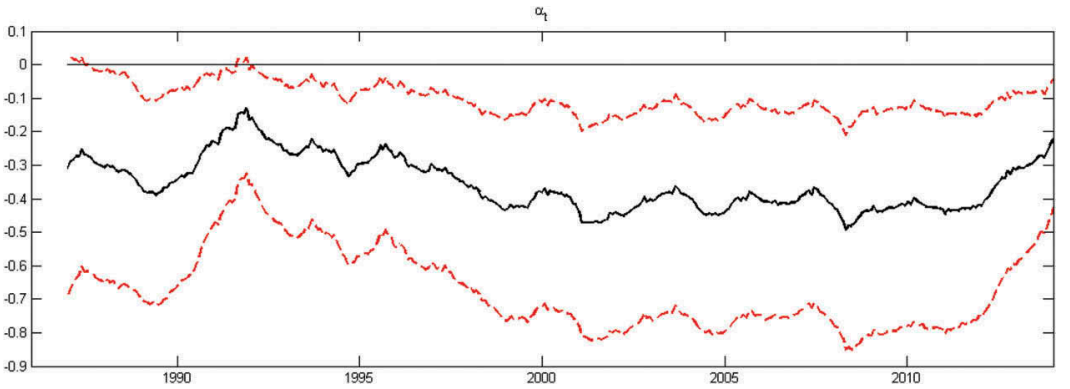

Figure 1. Aggregate level for the period 1986:01 to 2016:01.

Note: The solid line is the estimation and the dashed lines are the $10 \%$ confidence band.

${ }^{2}$ See http://data.worldbank.org/data-catalog/GDP-PPP-based-table. 
main sectors of IP, the effect is positive for Mining \& Quarrying, negative for Manufacturing, and positive but not statistically significant for Electricity \& Gas. When we look at the four subsectors of Mining \& Quarrying, the effects are negative for Mining of Coal \& Lignite, and positive for Extraction of Crude Petroleum \& Natural Gas, Mining of Metal Ores, and Other Mining \& Quarrying. When we look at the sub-sectors of Manufacturing, this effect is positive for six of the nine that we consider and negative for three of them. For the sub-sectors with a negative relationship, only one of these is statistically significant. Last, the relationship between output growth and its volatility decreases just after the 2008 financial crises for the sub-sectors of Manufacturing as well as for Mining \& Quarrying, but the sign of the relationship is unaltered across time. Thus, we see that the nature of the relationship changes across sectors.

The article is set out as follows: Section 2 describes the data and Section 3 presents the methodology. Section 4 discusses the empirical results and Section 5 concludes.

\section{Data}

We gathered all data from the Electronic Data Delivery System of the Central Bank of the Republic of Turkey. The time span that we employ is from January 1986 to January 2016. As noted above, the monthly IP series for aggregate output and its three main sectors (Mining \& Quarrying, Manufacturing, and Electricity \& Gas) were selected according to the NACE Rev.2 classification. Manufacturing covers 30 sub-sectors. We selected nine of these sub-sectors (see Figure 2) to demonstrate the different natures of the relationship between output growth volatility and output growth. To the best of our knowledge, no subsector data are available for Electricity \& Gas. For Mining \& Quarrying, the data set consists of all four sub-sectors (see Table A1). Data with NACE Rev. 2 classification is only available after January 2005; therefore, the data for the Manufacturing and Mining \& Quarrying sub-sectors are from January 2005 to January 2016. To account for seasonality, we use the X12 procedure. We calculate the growth rate for each series by $y_{t}=100^{*}$
$\left(Z_{t^{-}} Z_{t-1}\right) / Z_{t-1}$, where $Z_{t}$ is the series of interest at time $t$. A description of each series is given in Table A.1 of the Appendix.

\section{Methodology}

To investigate the impact of output volatility on output, we employ the TVP-SVM model introduced by Chan (2017), which can be given as follows:

$$
\begin{gathered}
y_{t}=\beta_{t}+\alpha_{t} e^{h t}+\varepsilon_{t}^{y}, \text { where } \varepsilon_{t}^{y} \sim N\left(0, e^{h_{t}}\right) \\
h_{t}=\mu+\phi\left(h_{t-1}-\mu+\varepsilon_{t}^{h}\right), \text { where } \varepsilon_{t}^{h} \sim N\left(0, \sigma^{2}\right) \\
\gamma_{t}=\gamma_{t-1}+\varepsilon_{t}^{y}, \text { where } \varepsilon_{t}^{y} \sim N(0, \Omega)
\end{gathered}
$$

where $y_{t}$ is the output growth at time $t, \beta_{t}$ is a vector of the TVPs for the constant term, and $h_{t}$ is the conditional variance. The coefficient $\alpha_{\mathrm{t}}$ captures the time-varying effect of volatility on output growth, $\Omega$ is a $2 \times 2$ covariance matrix, and the error terms $\varepsilon_{t}^{y}$ and $\varepsilon_{t}^{h}$ are assumed to be serially and mutually uncorrelated. The conditional variance function is specified in logarithmic form, in which $h_{t}$ follows a stationary $\operatorname{AR}(1)$ process with $|\phi|<1$, where $h_{1} \sim N$ $\left(\mu, \sigma^{2} /\left(1-\phi^{2}\right)\right)$. Equation (3) evolves a first-order random-walk process with a vector of coefficients $\gamma_{t}=\left(\alpha_{t}, \beta_{t}{ }^{\prime}\right)$, starting with $\gamma_{1} \sim N\left(\gamma_{0}, \Omega_{0}\right)$ for the constant matrices $\gamma_{0}$ and $\Omega_{0}$. The random-walk specification makes the model more flexible and enables us to capture both temporary and permanent shifts.

Equations (1) and (3) specify a nonlinear Gaussian state-space model. Because of the intractability of the likelihood function in Equations (1)-(3), the traditional Maximum Likelihood (ML) approaches cannot give strongly reliable estimates for the parameters. Chan (2017) estimates the Markov Chain Monte Carlo (MCMC) method based on band- and sparsematrix algorithms instead of on Kalman filters. Therefore, the specification reduces the dimension of the problem and makes the estimation easier to converge. In addition to the band- and sparsematrix algorithms, following Chan (2017), we adopt a Bayesian approach to simulate the joint posterior distribution. Therefore, MCMC is an efficient sampling approach that can simulate each type of state individually, as it exploits the 
(a) Manufacture of Basic Metals

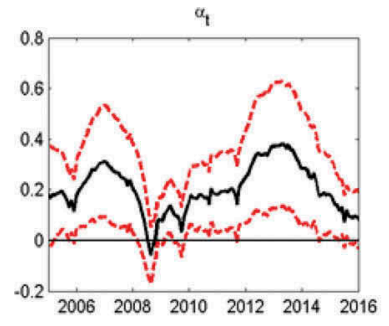

(d) Manufacture of Electrical Equipment

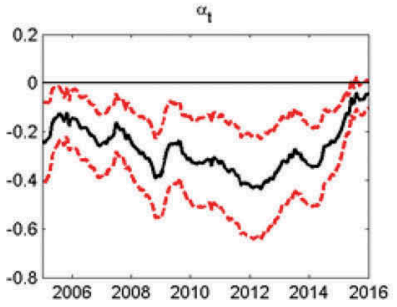

(g) Manufacture of Furniture

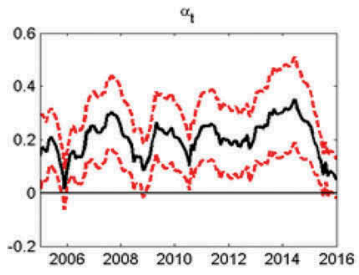

(b) Manufacture of Computer, Electronic, \&

Optical Products

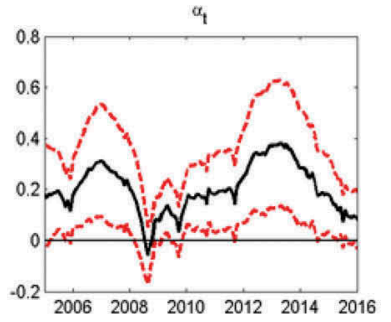

(e) Manufacture of Fabricated Metal Products (except Machinery \& Equipment)

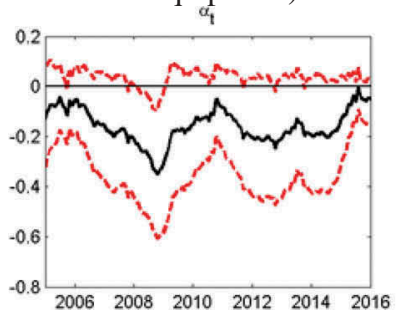

(h) Manufacture of Motor Vehicles, Trailers \& Semi-trailers

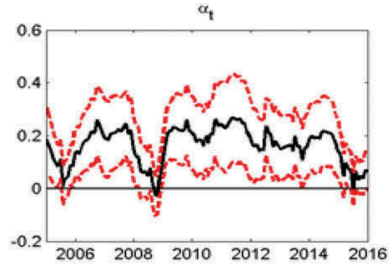

(c) Manufacture of Basic

Pharmaceutical Products \&

Pharmaceutical Preparations

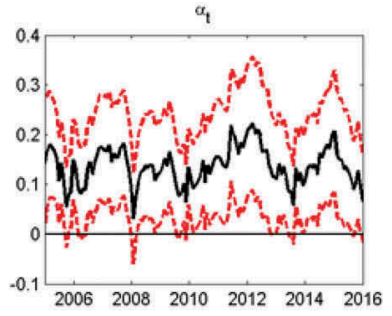

(f) Manufacture of Chemicals \& Chemical Products

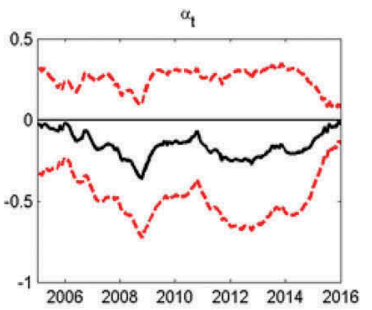

(i) Manufacture of Rubber \& Plastic Products

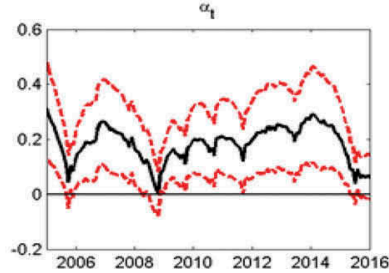

Figure 2. Disaggregate level for the period 1986:01 to 2016:01.

Note: The solid line is the estimation and the dashed lines are the $10 \%$ confidence band.

fact that the Hessian of the log-conditional density of the log-volatilities is a band matrix containing only a few nonzero elements arranged along a diagonal band (see Chan 2017 for further information).

\section{Empirical evidence}

Turkey is an emerging country. Thus, one may expect a negative impact of output growth volatility on output growth, as suggested by Keynes (1936) and Pindyck (1991), similar to the empirical studies of Ramey and Ramey (1995), Hakura (2007), and Berument, Dincer, and Mustafaoglu (2012). To determine whether the employed series are covariance stationary, as a necessary condition we perform unit root tests. The Augmented Dickey-Fuller and Phillips-Perron unit root tests suggest that all the series are difference stationary at the $1 \%$ significance level. Hence, TVP-SVM is admissible. We perform the analyses with the aggregate output (IP) series first. Figure 1. A plots the aggregate output growth series, and suggests it has high volatility. The series reaches its peak during crises periods in 1994, 2001, and 2008. Figure 1(b) exhibits the conditional variance estimates of aggregate output growth, which are for the measure of volatility $\left(h_{t}\right)$ with $90 \%$ confidence intervals. The middle line is the estimate of the conditional variances; the other two lines are the $90 \%$ confidence intervals. Figure 1(b) suggests that these estimates are statistically significant and have a value from 2.5 to 4.5 .

Sharp increases in volatility are indicators of economic or financial problems. In the sample, the highest volatility period is from 1992 to 1995. 
(a) Mining \& Quarrying growth volatility impact on

Mining \& Quarrying growth $\left(\alpha_{t}\right)$

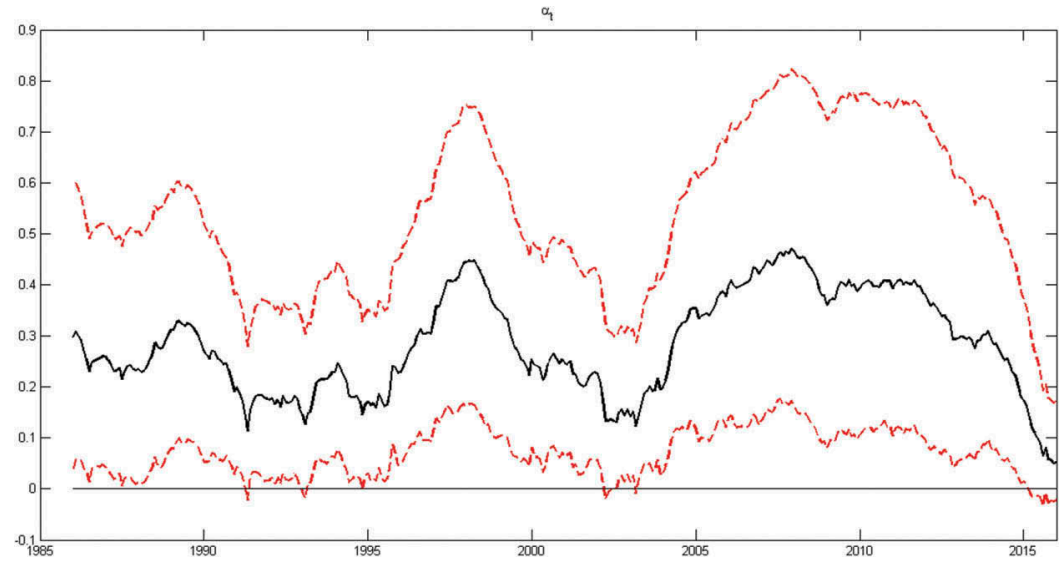

(b) Electricity \& Gas growth volatility impact on Electricity \& Gas growth $\left(\alpha_{t}\right)$

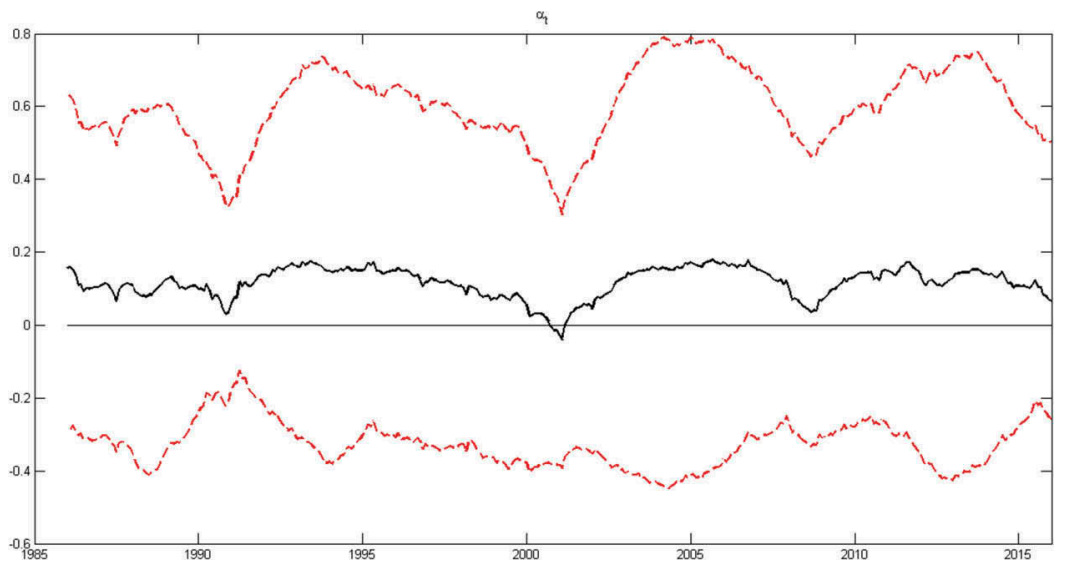

(c) Manufacturing growth volatility impact on Manufacturing growth $\left(\alpha_{t}\right)$

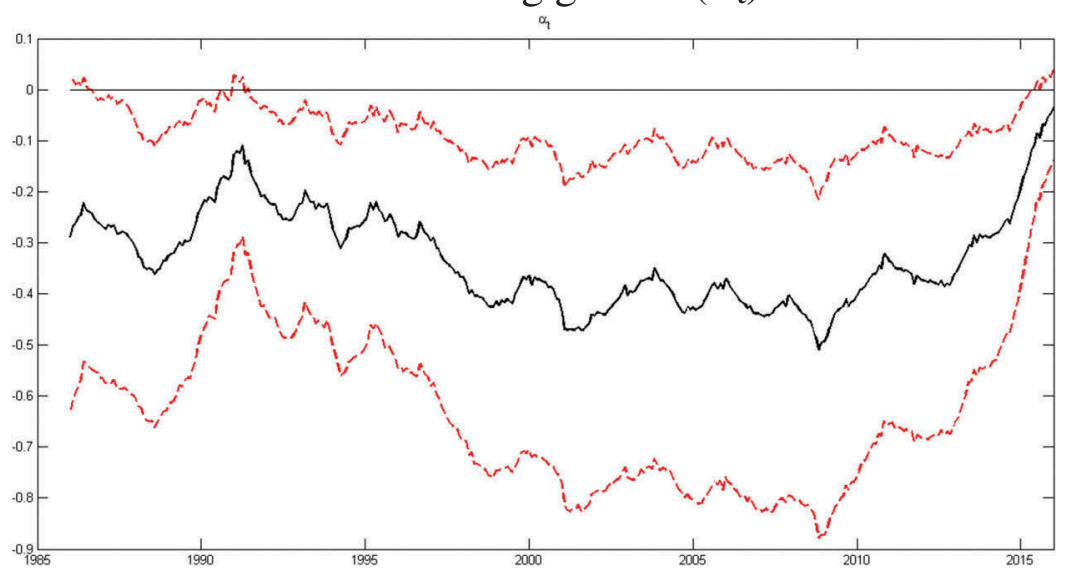

Figure 3. Sub-sectors of Manufacturing: growth volatility impact on their growth $\left(a_{t}\right)$ for the period 2005:01 to 2016:01. Note: The solid line is the estimation and the dashed lines are the $10 \%$ confidence band. 
(a) Mining of Coal \& Lignite

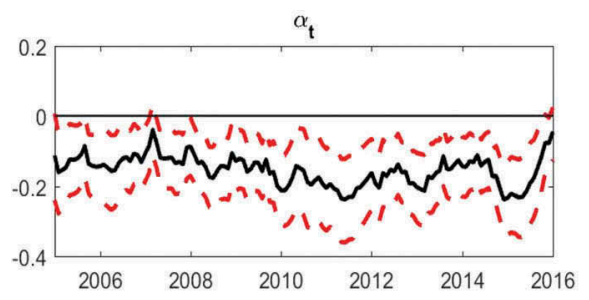

(c) Mining of Metal Ores

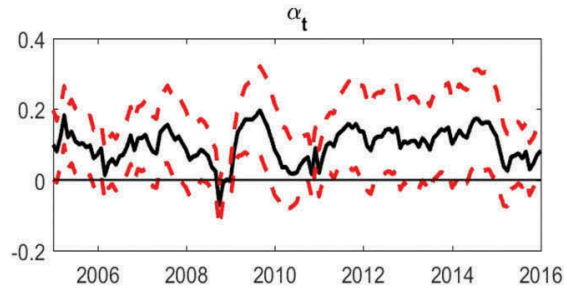

(b) Extraction of Crude Petroleum \& Natural Gas

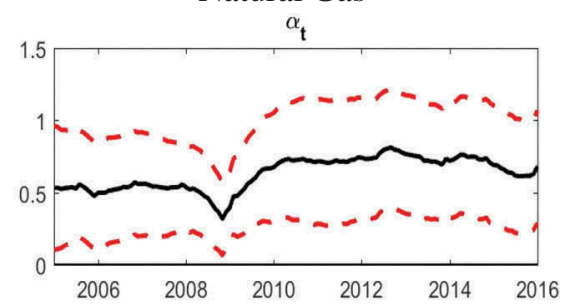

(d) Other Mining \& Quarrying

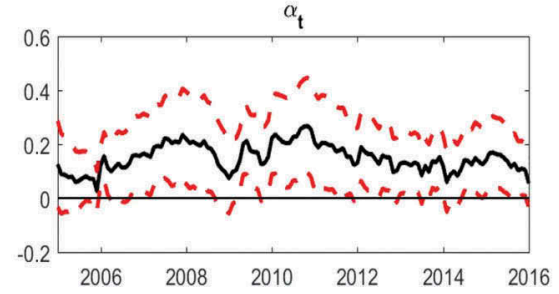

Figure 4. Sub-sectors of Mining \& Quarrying: growth volatility impact on their growth $\left(a_{t}\right)$ for the period 2005:01 to 2016:01.

Note: The solid line is the estimation and the dashed lines are the $10 \%$ confidence band.

Sharp increases are also observed in 2001 and 2008, and can be related to the April 1994 and November 2000-February 2001 economic crises and the 2008-2009 global crisis. Figure 1(c) plots for the time-varying effect of aggregate output growth volatility on aggregate output growth $\left(\alpha_{t}\right)$. The estimates are statistically significant and are negative in all periods. The lowest effect is in 1992, and the highest effects are in 2001 and 2009. The sharp changes in volatility (i.e. economic crises) are relevant to the impact of aggregate output growth volatility.

We repeat the analysis for the disaggregate level by using the three main sectors of IP. Figure 3(a) reports the time-varying impact $\left(\alpha_{\mathrm{t}}\right)$ of Mining \& Quarrying growth volatility on this sector's growth, in which this series has a $6.05 \%$ weight in IP. The estimated parameters are always positive and mostly statistically significant. To save space, we do not report the growth series of IP's three sectors, the four sub-sectors of Mining \& Quarrying, the nine sub-sectors of Manufacturing output, or their volatility measures. These results are available from the authors upon request.

Figure 3(b) reports growth and its volatility relationship for Electricity \& Gas production growth, which has a $12.44 \%$ weight in IP. The relationship is positive in all periods except for a brief negative period in 2001. However, this coefficient is not statistically significant for the whole period that we consider. Figure $3(\mathrm{c})$ is for Manufacturing growth, which has $81.51 \%$ weight in IP. Owing to this high weight of Manufacturing, similar behaviour is expected for the total IP series. Indeed, this is the case: the estimated parameters are statistically significant and negative for all periods that we consider. Both aggregate output (IP) and the Manufacturing sector show similar behaviour.

Next, we repeat the analyses for the four subsectors of Mining \& Quarrying. This relationship is always negative and almost always statistically significant for Mining of Coal \& Lignite. The relationship is always positive for Extraction of Crude Petroleum \& Natural Gas and Other Mining \& Quarrying, and mostly positive for Mining of Metal Ores. The positive relationship is always statistically significant for the Extraction of Crude Petroleum \& Natural Gas and usually statistically significant for Mining of Metal Ores and Other Mining \& Quarrying. Last, we repeat the analysis at the sectoral level by using the nine selected Manufacturing sub-sectors. Figure 2 reports the estimates for these sub-sectors. Similar to 
the whole IP, a negative relationship is observed only for three out of the nine sub-sectors. The estimates are not statistically significant for two sub-sectors in the period we consider; however, a positive relationship is observed for six of the nine sub-sectors, and the findings are mostly statistically significant for the majority of periods. Thus, we can safely conclude that while the relationships are different for all the IP series and its sub-sectors, the sign of the relationship for all the variables we consider changes little across time.

These results spark the following question: 'What determines the sign/magnitude of the relationship between output growth volatility and output growth?' Possible reasons for cross-sectoral differences in the sign/magnitude of this relationship might be differences in financial dependence, Research \& Development spending, and the degree of vertical integration. Unfortunately, these data are not available across sectors for Turkey so this line of research could not be pursued. However, in a future work, we plan to perform the analysis across countries and identify possible reasons for the difference in the sign/ magnitude of output growth volatility-output growth relationship.

A positive versus negative relationship between output growth and output growth volatility is important for its policy implications. In sectors where the relationship is positive, government should be allowing the output level to fluctuate in that sector's production and/or make entries into and exits from the sector easier. Policies to affect price and output should not be often employed. Moreover, government could encourage firms to invest longer term in areas that are subject to uncertainty but that have high potential to generate improvement in technology through innovation, rather than touting short-term projects that may have a lower level of productivity increases. On the other hand, sustaining a certain level of production and decreasing output volatility are important in maintaining a high level of growth for sectors with a negative relationship between output growth and output growth volatility. Making tax and subsidy policies and legal frameworks more predictable and credible, as well as using these fiscal tools to stabilize sector outputs by restraining fiscal institutions' involvement, might be advisable for these sectors.

\section{Conclusion}

We analyse the effect of output growth volatility on output growth for the period 1986 to 2016 for an emerging economy: Turkey. This effect is negative and statistically significant for total IP for the period that we consider. When we investigate this relationship for IP's three main sectors, the sign of the relationship changes across the sectors. It is positive and statistically significant for Mining \& Quarrying, positive and statistically insignificant for Electricity \& Gas, and, similar to total IP, negative and statistically significant for Manufacturing. We look further into this relationship for Mining \& Quarrying's four sub-sectors and nine selected sub-sectors in Manufacturing. In this deeper exploration, we also observe alternating signs for the effect of output growth volatility on output growth for these sub-sectors. Similar to Imbs (2007), this article reports a different effect of output growth volatility on output data at a different aggregation. However, Imbs finds a different relationship across countries versus across sectors; we find this different effect on total IP versus its sectors, as well as on a major sector and its sub-sectors.

\section{Acknowledgements}

We would like to thank Rana Nelson for her valuable suggestions

\section{Disclosure statement}

No potential conflict of interest was reported by the authors.

\section{ORCID}

M. Hakan Berument (D) http://orcid.org/0000-0003-22764741

\section{References}

Berument, M. H., N. N. Dincer, and Z. Mustafaoglu. 2012. "Effects of Growth Volatility on Economic Performance Empirical Evidence from Turkey." European Journal of 
Operational Research 217 (2): 351-356. doi:10.1016/j. ejor.2011.09.026.

Black, F. 1987. Business Cycles and Equilibrium. Cambridge: Blackwell.

Chan, J. C. C. 2017. "The Stochastic Volatility in Mean Model with Time-Varying Parameters: An Application to Inflation Modeling." Journal of Business and Economic Statistics $\quad 35 \quad$ (1): 17-28. doi:10.1080/ 07350015.2015.1052459.

Dabušinskas, A., D. Kulikov, and M. Randveer (2013). “The Impact of Volatility on Economic Growth." Bank of Estonia Working Paper No. wp2012-7. Bank of Estonia. https://ideas.repec.org/p/eea/boewps/wp2012-7.html

Dawson, J. W. 2015 January 1. "The Empirical VolatilityGrowth Relationship: Is Economic Freedom the Missing Link?" The Journal of Private Enterprise 30 (2): 61-82.

Evans, M. 1991. "Discovering the Link between Inflation Rates and Inflation Uncertainty." Journal of Money, Credit and Banking 23 (2): 169-184. doi:10.2307/ 1992775.

Fang, W.-S., and S. M. Miller. 2008. "The Great Moderation and the Relationship between Output Growth and Its Volatility." Southern Economic Journal 74 (3): 819-838.

Friedman, F. 1968. “The Role of Monetary Policy." American Economic Review 58 (1): 1-17.

Hakura, D. S. 2007. Output Volatility and Large Output Drops in Emerging Market and Developing Countries. Washington, DC: IMF.

Imbs, J. (2002). "Why the Link between Volatility and Growth Is Both Positive and Negative." CEPR Discussion Paper No. 3561. C.E.P.R. Discussion Papers. doi: 10.1044/ 1059-0889(2002/er01).

Imbs, J. 2007. "Growth and Volatility." Journal of Monetary Economics 54 (2007): 1848-1862. doi:10.1016/j. jmoneco.2006.08.001.

Keynes, J. M. 1936. "The General Theory of Employment, Interest and Money." Journal of the Royal Statistical Society 99 (2): 383. doi:10.2307/ 2980590 .
Koopman, S. J., and E. Hol Uspensky. 2002. "The Stochastic Volatility in Mean Model: Empirical Evidence from International Stock Markets." Journal of Applied Econometrics 17 (6): 667-689. doi:10.1002/jae.652.

Kose, M. A., E. S. Prasad, and M. E. Terrones. 2006. "How Do Trade and Financial Integration Affect the Relationship between Growth and Volatility?" Journal of International Economics 69 (1): 176-202. doi:10.1016/j. jinteco.2005.05.009.

Lee, J. 2010. "The Link between Output Growth and Volatility: Evidence from a GARCH Model with Panel Data." Economics Letters 106 (2): 143-145. doi:10.1016/j. econlet.2009.11.008.

Lucas, R. E. 1972. "Expectations and the Neutrality of Money." Journal of Economic Theory 4 (2): 103-124. doi:10.1016/0022-0531(72)90142-1.

Phelps, E. S. 1968. "Money-Wage Dynamics and LaborMarket Equilibrium." Journal of Political Economy 76 (4, Part 2): 678-711. doi:10.1086/259438.

Pindyck, R. S. 1991. "Irreversibility, Uncertainty, and Investment." Journal of Economic Literature 29 (3): 1110-1148.

Ramey, G., and V. A. Ramey. 1995. "Cross-Country Evidence on the Link between Volatility and Growth." American Economic Review 85 (5): 1138-1151.

Sandmo, A. 1970. "The Effect of Uncertainty on Saving Decisions." The Review of Economic Studies 37 (3): 353. doi:10.2307/2296725.

Speight, A. E. H. 1999. "UK Output Variability and Growth: Some Further Evidence." Scottish Journal of Political Economy 46 (2): 175-184. doi:10.1111/14679485.00127.

Tsouma, E. 2014. “The Link between Output Growth and Real Uncertainty in Greece: A Tool to Speed up Economic Recovery?" Theoretical Economics Letters 04 (01): 91-97. doi:10.4236/tel.2014.41015.

Zagler, M. 2016. "Empirical Evidence on Growth and Business Cycles.” Empirica 1-20. doi:10.1007/s10663-0169336-4. 


\section{Table A.1: Data Sources}

\begin{tabular}{|c|c|c|c|}
\hline Variable & Definition & CBRT Code & Source \\
\hline \multicolumn{4}{|c|}{ Aggregate Output } \\
\hline \multirow[t]{4}{*}{ Industrial Production ${ }^{\mathrm{a}}$} & Industrial Production $(2010=100)$ & TP.UR4.U01 & CBRT, EDDS \\
\hline & 1986/01-2000/04 & TP.TSY01 & \\
\hline & $2000 / 05-2004 / 12$ & TP.N2SY01 & \\
\hline & 2005/01-2016/01 & & \\
\hline \multicolumn{4}{|c|}{ Aggregate Output Sub-sectors } \\
\hline Mining \& Quarrying ${ }^{a}$ & Base year $(2010=100)^{\mathrm{a}} 1986 / 01-2000 / 04$ & TP.UR4.U02 & CBRT, EDDS \\
\hline & $2000 / 05-2004 / 12$ 2005/01-2016/01 & $\begin{array}{l}\text { TP.TSY02 } \\
\text { TP.N2SY07 }\end{array}$ & \\
\hline \multirow[t]{3}{*}{ Electricity \& Gas ${ }^{\mathrm{a}}$} & Base year $(2010=100)^{a} 1986 / 01-2000 / 04$ & TP.UR4.U17 & CBRT, EDDS \\
\hline & $2000 / 05-2004 / 12$ 2005/01-2016/01 & TP.TSY30 & \\
\hline & & TP.N2SY37 & \\
\hline \multirow[t]{3}{*}{ Manufacturing $^{a}$} & Base year $(2010=100)^{\mathrm{a}} 1986 / 01-2000 / 04$ & TP.UR4.U07 & CBRT, EDDS \\
\hline & $2000 / 05-2004 / 12$ 2005/01-2016/01 & TP.TSY07 & \\
\hline & & TP.N2SY12 & \\
\hline \multicolumn{4}{|c|}{ Selected Sub-sectors of Manufacturing } \\
\hline Manufacture of Basic Metals & Base year $(2010=100) 2005 / 01-2016 / 01$ & TP.N2SY27 & CBRT, EDDS \\
\hline Manufacture of Computer, Electronic \& Optical Products & Base year $(2010=100) 2005 / 01-2016 / 01$ & TP.N2SY29 & CBRT, EDDS \\
\hline Manufacture of Basic Pharmaceutical Products \& Pharmaceutical Preparations & Base year $(2010=100) 2005 / 01-2016 / 01$ & TP.N2SY24 & CBRT, EDDS \\
\hline Manufacture of Electrical Equipment Products (except Machinery \& Equipment) & Base year $(2010=100) 2005 / 01-2016 / 01$ & TP.N2SY30 & CBRT, EDDS \\
\hline Manufacture of Fabricated Metal Products (except Machinery \& Equipment) & Base year $(2010=100) 2005 / 01-2016 / 01$ & TP.N2SY28 & CBRT, EDDS \\
\hline Manufacture of Chemicals \& Chemical Products & Base year $(2010=100) 2005 / 01-2016 / 01$ & TP.N2SY23 & CBRT, EDDS \\
\hline Manufacture of Furniture & Base year $(2010=100) 2005 / 01-2016 / 01$ & TP.N2SY34 & CBRT, EDDS \\
\hline Manufacture of Motor Vehicles, Trailers \& Semi-trailers & Base year $(2010=100) 2005 / 01-2016 / 01$ & TP.N2SY32 & CBRT, EDDS \\
\hline Manufacture of Rubber \& Plastic Products & Base year $(2010=100 \mathrm{~T}) 2005 / 01-2016 / 01$ & TP.N2SY25 & CBRT, EDDS \\
\hline \multicolumn{4}{|c|}{ Mining \& Quarrying } \\
\hline Mining of Coal \& Lignite & Base year $(2010=100) 2005 / 01-2016 / 01$ & TP.N2SY08 & CBRT, EDDS \\
\hline Extraction of Crude Petroleum \& Natural Gas & Base year $(2010=100) 2005 / 01-2016 / 01$ & TP.N2SY09 & CBRT, EDDS \\
\hline Mining of Metal Ores & Base year $(2010=100) 2005 / 01-2016 / 01$ & TP.N2SY10 & CBRT, EDDS \\
\hline Other Mining \& Quarrying & Base year $(2010=100) 2005 / 01-2016 / 01$ & TP.N2SY11 & CBRT, EDDS \\
\hline
\end{tabular}

Notes: Abbreviations and their meanings: CBRT: Central Bank of the Republic of Turkey; EDDS: Electronic Data Delivery System.

a Combination of the given series is used for the entire period. 